\title{
Impulsivity and the Self-Defeating Behavior of Narcissists
}

\author{
Simine Vazire \\ Department of Psychology \\ The University of Texas at Austin \\ David C. Funder \\ Department of Psychology \\ University of California, Riverside
}

\begin{abstract}
Currently prominent models of narcissism (e.g., Morf \& Rhodewalt, 2001) primarily explain narcissists' self-defeating behaviors in terms of conscious cognitive and affective processes. We propose that the disposition of impulsivity may also play an important role. We offer 2 forms of evidence. First, we present a meta-analysis demonstrating a strong positive relationship between narcissism and impulsivity. Second, we review and reinterpret the literature on 3 hallmarks of narcissism: self-enhancement, aggression, and negative long-term outcomes. Our reinterpretation argues that impulsivity provides a more parsimonious explanation for at least some of narcissists' self-defeating behavior than do existing models. These 2 sources of evidence suggest that narcissists' quest for the status and recognition they so intensely desire is thwarted, in part, by their lack of the self-control necessary to achieve those goals.
\end{abstract}

Narcissists are a puzzle. Their bragging and arrogance interferes with the attainment of the status and recognition they so poignantly desire. Why do they continually undermine themselves in this way? The research literature appears to have achieved some consensus about the nature of sub-clinical narcissism ${ }^{1}$ with respect to underlying cognitive, social, and affective processes (e.g., Morf \& Rhodewalt, 2001). The consensual model serves as a solid foundation for integrating narcissism research, and provides a partial explanation for narcissists' perplexing behavior, but it relies heavily on conscious cognitive processes and omits an important category of explanatory variables: dispositions. We shall argue that one possible key to the puzzle posed by narcissists' behavior is that they are dispositionally impulsive: They lack the self-control necessary to inhibit the behaviors that thwart the attainment of their goals.

\footnotetext{
${ }^{1}$ Throughout the paper, we use the term narcissism to refer to subclinical narcissism.

Portions of this research were supported by National Institute of Mental Health Grant R01-MH52391 to James Pennebaker. Data gathering for the Riverside Accuracy Project was supported by National Institute of Mental Health Grant R01-MH42427 to David Funder.

We are grateful to Sam Gosling, Del Paulhus, and Kathleen Vohs for their helpful comments on this article, and to Matthias Mehl for making his data available.

Correspondence should be sent to Simine Vazire, Department of Psychology, The University of Texas at Austin, 1 University Station, A800, Austin, TX 78712. E-mail: simine@mail.utexas.edu
}

This article begins by proposing that the widely accepted cognitive-affective processing model presented by Morf and Rhodewalt (2001) be extended to include dispositional impulsivity. We then review the empirical evidence for our proposal by presenting a meta-analysis of the relationship between narcissism and impulsivity, including unpublished results from two large data sets. Although researchers have been tangentially aware of this relationship for decades, none have looked to impulsivity as a central explanation for narcissists' behavior. The final section of the article examines the implications of our proposal by reinterpreting major findings in the literature in light of the relationship between narcissism and impulsivity. By incorporating dispositional impulsivity into existing models of narcissism, our proposal seeks both to extend and to simplify the understanding of narcissism.

\section{Theoretical Framework}

Narcissism is generally seen as deriving from an attempt to regulate and maintain unrealistically high levels of self-esteem (Raskin, Novacek, \& Hogan, 1991b; Robins \& John, 1997). Narcissists' self-views are on the one hand lofty (Paulhus \& John, 1998), making it difficult for them to find affirmation, and on the other hand vulnerable or unstable (Jordan, Spencer, Zanna, Hoshino-Browne, \& Correll, 2003), making such affirmation particularly important. This combination of arrogance and vulnerability is one of the paradoxes that 
Morf and Rhodewalt (2001) addressed in their cognitive-affective processing model. As they and others argue (e.g., Westen, 1990), much of narcissists' cognitive, affective, and behavioral responses are in the service of defending and affirming an unrealistic self-concept.

How do narcissists go about the difficult task of maintaining a self-concept that is both overly positive and highly fragile? Not very successfully. The research literature shows that narcissists engage in behaviors such as bragging, derogating others, reacting to ego threats with hostility and aggression, making internal attributions for success and external attributions for failure, and overestimating future outcomes and performance even in the face of disconfirming feedback. Clearly these are not behaviors well-chosen to earn the respect and esteem of others. Indeed, research has shown that narcissists are disliked by their peers (after making a fleeting positive first impression; Paulhus, 1998), are psychologically maladjusted (Colvin, Block, \& Funder, 1995), and become increasingly unhappy and disengaged from academics over the course of college (Robins \& Beer, 2001). In short, "as they yearn and reach for self-affirmation, [narcissists] destroy the very relationships on which they are dependent" (Morf \& Rhodewalt, 2001, p. 179).

Cognitive-affective processing models (e.g., Morf $\&$ Rhodewalt, 2001) maintain that narcissists engage in ineffective or even counterproductive interpersonal strategies because they are insensitive to others' concerns. In other words, although their behavior seems self-defeating to the outside observer, it is actually a deliberate, though ill-conceived, strategy that makes sense from the point of view of their internal subjective logic. We propose a more parsimonious explanation for at least some of these self-defeating behaviors: The behaviors are not strategic at all, narcissists simply can't help themselves.

We propose that narcissists suffer from a dispositional lack of self-control (i.e., impulsivity, a concept closely akin to ego undercontrol; Block, 2002; Block \& Block, 1980), and this contributes to their inability to meet the high self-regulatory demands of an inflated, unstable self-concept. As a result, they are unable to successfully negotiate their social environments to obtain the recognition they crave. As we point out in our reinterpretation of the narcissism literature, many of narcissists' behaviors may provide temporary immediate gratification of their desire for recognition, but it comes at the cost of long-term success-the classic framework of the concept of delay of gratification (e.g., Funder, Block \& Block, 1983; Mischel \& Ayduk, 2002).

In support of our proposal, we present the results from a meta-analysis of the published correlations between narcissism and impulsivity along with unpublished results from two large data sets examining the relationship between narcissism and impulsivity. Then, we review the literature on narcissism and argue that much of narcissists' behavior can be reinterpreted and understood in terms of patterns of behavior characteristic of impulsive people. Specifically, we reinterpret the literature with respect to three self-defeating behaviors that are well-established hallmarks of narcissism: self-enhancement, aggression, and negative long-term outcomes.

\section{A Meta-Analysis of the Empirical Evidence for our Proposal}

In the early days of empirical research on narcissism, impulsivity appeared frequently among long lists of associated traits. In one of the most cited early articles, Raskin and Terry (1988) described narcissists as "relatively dominant, extraverted, exhibitionistic, aggressive, impulsive, self-centered, subjectively self-satisfied, self-indulgent, and nonconforming" (p. 899). Several of these characteristics have been studied extensively (e.g., aggression, Bushman \& Baumeister, 1998; self-centeredness, Robins \& John, 1997), but impulsivity seems to have largely escaped subsequent research attention.

An exception can be found in the literature on clinical narcissism (Narcissistic Personality Disorder; NPD). Although NPD and subclinical narcissism have been traditionally treated as separate lines of research, the clinical literature provides a strong basis for suspecting a central role for impulsivity in subclinical narcissism. Hollander and Rosen (2000) argued that impulsivity is an important component of many disorders, including NPD, and that a complete understanding and successful treatment of narcissism in particular requires an understanding of the role of impulsivity. Similarly, Casillas and Clark (2002) found that the correlation between NPD and impulsivity was $.35(p<$ .01 ) when impulsivity was measured with the Schedule for Nonadaptive and Adaptive Personality (SNAP; Clark, 1993), and .41 $(p<.01)$ when measured with the Barratt Impulsivity Scale (BIS; Patton, Stanford, \& Barratt, 1995). Furthermore, Casillas and Clark found that "In the case of narcissistic PD, its entire relationship with substance abuse was [statistically] explained by [impulsivity and self-harm]" (p. 434).

Although little or no research has focused directly on the role of impulsivity in subclinical narcissism, many of the early construct-validation studies of narcissism scales reported correlations with large batteries of other measures, including measures of impulsivity. These correlations were never the primary concern and often were not even mentioned in the text of the articles. The validation studies usually reported all correlations between narcissism and the other constructs assessed, regardless of direction or size. Thus, the 
relationship between narcissism and impulsivity reported in this literature is unlikely to be a biased estimate (i.e., there is less likely to be a "file-drawer" problem of nonsignificant or disconfirming findings that have remained unpublished).

Our meta-analysis began with a meticulous three-step search. Because we were interested in casting a broad net and obtaining empirical articles on narcissism, we searched the PsycINFO database. We limited our search to journal articles and book chapters published in English since 1979, when a consistent definition of subclinical narcissism began to emerge. In the first step of the search, we searched for papers with "narciss*" (e.g., "narcissism" or "narcissistic"), "NPI", or "self-enhancement" in the title. To exclude papers on clinical populations or referring to clinical narcissism, we excluded papers with the words "psychoanal*" (e.g., "psychoanalytic" or "psychoanalysis") and "disorder" in the default search fields (i.e., title, abstract, key phrase, subjects, table of contents, and author). This yielded 347 articles and 35 book chapters.

In the second step of the search, we sought to identify those papers reporting a correlation between narcissism and some measure of impulsivity. To do this, we searched the 382 papers for any of the following words or phrases, using the "All Text" field to search for impuls* (e.g., "impulsivity," "impulsiveness," "impulse-control," etc.), self-control, ego-control, constraint, ability to delay gratification, and patience or impatience. However, because we suspected that these correlations would often be peripheral to the main subject of the papers, we also skimmed the abstracts from all 382 papers obtained in the first step of the search and retained those that included instruments that could be used to measure impulsivity (e.g., the CAQ; Block, 1961). From the 382 papers, we retained 81 that could potentially report correlations between impulsivity and narcissism.

In the third step of the search process, we carefully examined all 81 of these papers and retained those with an effect size estimate for the relationship between narcissism and impulsivity. This yielded eight articles containing 17 effect size estimates, which are shown in Table 1 along with samples sizes and significance levels. The measures of narcissism and impulsivity came from self-reports, observer ratings, informant ratings, and clinician ratings. Some of the narcissism measures, such as those based on the CAQ (e.g., Wink, 1992) contained some content overlap with the impulsivity measures, but most, such as the Narcissistic Personality Inventory (NPI; Raskin \& Terry, 1988) did not.

Table 1 also includes six previously unpublished correlations between narcissism and impulsivity from two large data sets. These data sets include a combination of self-reports, reports from well-acquainted in- formants, and ratings by clinicians. In the first data set (Vazire \& Mehl, 2004), narcissism scores were obtained from participants' NPI scores (aggregated across two assessments) and from the aggregate of three informant ratings of the participants on a 4-item measure (Kurt \& Paulhus, 2004). Both measures of narcissism had adequate reliabilities (NPI: test-retest $r$ $=.89$; informant-rated narcissism: ICC $[1, k]=.73$ ). Impulsivity ratings were obtained from two facets of the NEO Personality Inventory-Revised (NEO PI-R; Costa \& McCrae, 1992) both aggregated across two assessments: impulsivity, a facet of neuroticism, and deliberation (reversed), a facet of conscientiousness. These two facets were combined into a single reliable composite; $\operatorname{ICC}(2, k)=.84$.

In the second dataset (The Riverside Accuracy Project, Phase II ${ }^{2}$; Funder, 2004), narcissism was also assessed using the NPI; ICC $(2, k)=.83$. Impulsivity scores were obtained from four sources. The first was participants' self-reports on Block's ego undercontrol scale (UC; Letzring, Block, \& Funder, in press); ICC $(2, k)=.77$. The UC scale assesses individual differences in ego-control (Block \& Block, 1980). High scorers (undercontrolled individuals) are "unable to delay gratification, have fluctuating emotions, and are spontaneous, easily distracted, and relatively unbound by social norms" (Letzring et al., in press). Impulsivity scores were also derived from self-reports on the CAQ (Block, 1961). Participants rated themselves on items of the CAQ using a 9-point Likert-type rating method (for a description, see Letrzing et al., in press), and their profiles were then correlated with the existing CAQ prototype for ego undercontrol. This correlation (adjusted using Fisher's $r$-to- $z$ formula) was then used as an index of self-rated impulsivity. As a third index of impulsivity, one of several clinicians also rated each of the participants on the CAQ using the Q-sort method. The clinician had conducted 1-hour long life history interview with the participant. In some cases, the rating of a second clinician who had viewed a video of the interview was also available. In those cases, the two clinicians' CAQ ratings were aggregated; otherwise, the single CAQ rating was used. The aggregate was correlated with the CAQ ego undercontrol prototype and these transformed correlations served as our third index of impulsivity. Finally, each participant was also rated on the CAQ by one or two acquaintances who served as informants. The informant $\mathrm{CAQ}$ ratings were aggregated and the aggregate was correlated with the CAQ ego undercontrol prototype. This transformed correlation served as our fourth index of impulsivity.

\footnotetext{
${ }^{2}$ Data analyses of this large, new data set are in the early stage. One publication has reported correlates of Block's measures of ego-resiliency and ego control (Letzring et al., in press). These analyses do not overlap with others, completed or planned.
} 
Table 1. Correlations Between Narcissism and Impulsivity

\begin{tabular}{|c|c|c|c|c|c|}
\hline Study & Measure of Narcissism & Measure of Impulsivity & $N$ & Sample ${ }^{a}$ & $r$ \\
\hline Emmons (1984) & NPI & $16 \mathrm{PF}$ "self-control" (reversed) & 65 & 1 & -.03 \\
\hline \multirow[t]{3}{*}{ Raskin and Terry (1988) } & NPI & ACL "self-control" (reversed) & 57 & 2 & $.63 * *$ \\
\hline & NPI & CPI "self-control" (reversed) & 57 & 2 & $.36^{* *}$ \\
\hline & NPI & $\begin{array}{l}\text { Observer rating: ACL "patient" } \\
\text { (reversed) }\end{array}$ & 57 & 2 & $.55^{* *}$ \\
\hline \multirow[t]{2}{*}{ Raskin and Novacek (1989) } & NPI & MMPI ego-control (reversed) & 57 & 2 & $.43 * * \mathrm{~b}$ \\
\hline & & & 193 & 3 & $.40 * *$ \\
\hline \multirow[t]{2}{*}{ Wink and Gough (1990) } & CPI narcissism & CPI self-control (reversed) & 350 & 4 & $.67 * *$ \\
\hline & MMPI narcissism & CPI self-control (reversed) & 350 & 4 & $.60 * *$ \\
\hline \multirow[t]{2}{*}{ Wink (1991) } & $\begin{array}{l}\text { MMPI narcissism (Factor 2: } \\
\quad \text { Grandiosity-Exhibitionism) }^{\mathrm{b}}\end{array}$ & CPI self-control (reversed) & 350 & 4 & $.52 * *$ \\
\hline & $\begin{array}{l}\text { MMPI narcissism (Factor 2: } \\
\text { Grandiosity-Exhibitionism) }\end{array}$ & Spouse rating: ACL "impulsive" & 152 & 4 & $.22 * *$ \\
\hline \multirow[t]{4}{*}{ Wink (1992) } & $\begin{array}{l}\text { CAQ Narcissism prototype } \\
\text { ("Willfulness" subscale) }\end{array}$ & CPI self-control (reversed) & 102 & 5 & $.30 * * \mathrm{c}$ \\
\hline & & & 350 & 4 & $.34 * *$ \\
\hline & $\begin{array}{l}\text { CAQ Narcissism prototype } \\
\text { ("Willfulness" subscale) }\end{array}$ & Spouse rating: ACL "impulsive" & 152 & 4 & $.28^{*}$ \\
\hline & $\begin{array}{l}\text { CAQ Narcissism prototype } \\
\text { ("Willfulness" subscale) }\end{array}$ & Spouse rating: ACL "impatient" & 152 & 4 & $.26^{*}$ \\
\hline \multirow[t]{2}{*}{$\begin{array}{l}\text { Colvin, Block, and Funder } \\
\text { (1995) }\end{array}$} & $\begin{array}{l}\text { Discrepancy between positivity } \\
\text { of self and clinician ratings } \\
\text { (on CAQ) }\end{array}$ & $\begin{array}{l}\text { Peer rating: CAQ item 53: "unable } \\
\text { to delay gratification" }\end{array}$ & 30 & 6 & $.40 * * \mathrm{~d}$ \\
\hline & & & 32 & & $.35 * *$ \\
\hline Wink and Donahue (1997) & MMPI Narcissism & $\begin{array}{l}\text { BPS constraint subscale } \\
\text { (reversed) }\end{array}$ & 106 & 8 & $.35^{*}$ \\
\hline \multirow[t]{2}{*}{ Vazire and Mehl (2004) } & NPI & $\begin{array}{l}\text { NEO PI-R self-report (N5 \& } \\
\text { C6-reversed) }\end{array}$ & 80 & 9 & $.27 *$ \\
\hline & Informant ratings & $\begin{array}{l}\text { NEO PI-R self-report (N5 \& } \\
\text { C6-reversed) }\end{array}$ & 78 & 9 & $.29 *$ \\
\hline \multirow[t]{4}{*}{ RAP II (Funder, 2004) } & NPI & $\begin{array}{l}\text { Ego-undercontrol scale score } \\
\text { (self-report) }\end{array}$ & 196 & 10 & $.32 * *$ \\
\hline & NPI & $\begin{array}{l}\text { Ego-undercontrol prototype match } \\
\text { (CAQ; self-report) }\end{array}$ & 198 & 10 & $.39 * *$ \\
\hline & NPI & $\begin{array}{l}\text { Ego-undercontrol prototype match } \\
\text { (CAQ; clinicians' ratings) }\end{array}$ & 195 & 10 & $.35 * *$ \\
\hline & NPI & $\begin{array}{l}\text { Ego-undercontrol prototype match } \\
\text { (CAQ; informants' ratings) }\end{array}$ & 190 & 10 & -.01 \\
\hline $\begin{array}{l}\text { Weighted mean of all } 23 \\
\text { effect sizes }^{\mathrm{f}}\end{array}$ & & & 3549 & & $.41 * *$ \\
\hline $\begin{array}{l}\text { Weighted mean of effects } \\
\text { sizes for the } 10 \\
\text { independent samples }\end{array}$ & & & $1,213^{\mathrm{g}}$ & & $.34 * *$ \\
\hline
\end{tabular}

Note. All measures are self-reports unless otherwise indicated. RAP II = Riverside Accuracy Project, Phase II, NPI = Narcissistic Personality Inventory (Raskin \& Hall, 1979; 1981), MMPI = Minnesota Multiphasic Personality Inventory, CPI = California Personality Inventory (Gough, 1957; 1987), ACL = Adjective Checklist (Gough \& Heilbrun, 1983), CAQ = California Adult Q-set (Block, 1961), BPS = Boredom Proneness Scale (Farmer \& Sundberg, 1986), NEO PI-R = NEO Personality Inventory-Revised (Costa \& McCrae, 1992); N5 = Impulsivity facet of NEO PI-R; C6 = Deliberation facet of NEO PI-R.

$* p<.05 . * * p<.01$.

aThe 23 effect sizes reported in this table come from 10 independent samples. We have numbered the samples to indicate which effect sizes come from the same sample.

bWink (1991) characterized the first MMPI narcissism factor as covert narcissism and the second as overt narcissism.

${ }^{\mathrm{c}}$ Results were reported for two separate samples.

${ }^{\mathrm{d}}$ Results reported separately for men (top correlation) and women (bottom correlation).

'The constraint subscale of the BPS measures: "feelings of impulsivity and restlessness in response to external constraints on behavior" (Wink \& Donahue, 1997, p. 138).

${ }^{\mathrm{f}}$ The weighted means are weighted by $n-3$.

gThe $N$ for the weighted mean reflects the number of unique participants represented in this table (i.e., participants represented in more than one analysis were only counted once). 
As the results of our meta-analysis demonstrate (Table 1), there is strong evidence for a relationship between impulsivity and narcissism. Narcissists are described as impulsive, impatient, unable to delay gratification, and lacking in self-control by themselves, their spouses, their peers, and unacquainted observers. All but 2 of the 23 correlations (91\%) were significant and in the predicted direction. The consistency in our findings is particularly impressive considering the breadth of narcissism and impulsivity measures that were used.

To obtain an estimated effect size based on these correlations, we followed the procedures for meta-analysis recommended by Rosenthal (1995). Before averaging the correlations, we transformed them using Fisher's $r$-to- $z$ formula. However, all of the effect size estimates we report have been transformed back into correlations. The mean of all 23 correlations between narcissism and impulsivity was .37 , the median was .35 , and the weighted mean (weighted by $\mathrm{n}-3$ ) was .41. The $95 \%$ confidence interval of this estimate ranges from .38 to .44 , indicating that the effect size estimate is significantly different from zero.

However, as we note in Table 1, these are not all independent effect sizes. The 23 effect sizes are drawn from only 10 independent samples. Thus, we also computed the mean effect sizes of the 10 independent samples and conducted a meta-analysis of these effects. As shown in the last row of Table 1, the weighted mean of this set of effect sizes is .34 . The $95 \%$ confidence interval for this estimate ranges from .28 to .40 , once again indicating that the effect size estimate is significantly different from zero.

To determine whether the effect sizes from the 10 independent samples are likely to be estimating the same population mean, we computed the heterogeneity statistic $Q$. The value for $Q$ was slightly above what would be expected by chance, $\chi^{2}(9)=17.6, \mathrm{p}<.05$. This suggests that the variance in the estimates exceeds what would be expected based on sampling error. A follow-up analysis shows that this heterogeneity is due mostly to a single outlier: of the 10 independent effect sizes, all range from .25 to .50 except for one (Emmons, 1984; -.03). When this effect size is removed from the meta-analysis, the heterogeneity drops to nonsignificant levels, $\chi^{2}(8)=7.8$, n.s.

This clear pattern of results supports Raskin and Terry's (1988) suggestion that impulsivity is one of the defining characteristics of narcissism. Indeed, in Wink and Gough's (1990) study, both measures of narcissism correlated more strongly with CPI self-control $(r \mathrm{~s}=-.60,-.67, p \mathrm{~s}<.01)$ than with any of the other 19 CPI subscales, and in Raskin and Terry's study narcissism correlated more strongly with the ACL item "patient" $(r=-.55, p<.01)$ than with any of the 299 other ACL items except for "submissive" $(r=-.57, p<.01)$.
Based on the consistent evidence in the clinical, social, and personality literatures, and on our own analyses of two multi-method datasets, it is clear that a relationship exists between narcissism and impulsivity. Despite their penchant for self-enhancement, narcissists consistently rate themselves as impulsive, and they are also seen by others as impulsive.

Having provided evidence that narcissists are indeed impulsive, we turn to our central point: that this relationship helps explain their self-defeating behavior. In our review, we shall compare our dispositional explanation to Morf and Rhodewalt's (2001) cognitive-affective processing model. Our goal is not to refute the existing model of narcissism, but to show that a dispositional explanation is in some respects more parsimonious, and should also be included.

\section{A Review and Reinterpretation of Narcissists' Self-Defeating Behavior}

Most researchers who have examined the behavioral responses of narcissists have explained narcissists' behavior in terms of thoughts and intentions. For example, Baumeister, Bushman, and Campbell (2000) wrote: "Another question is what exactly narcissistic people hope to accomplish by responding violently to an insult" (p. 29). Questions like this implicitly assume that narcissists' behavior is driven by their cognitive appraisals, and even that it may be entirely within their conscious understanding and volitional control. In contrast, a dispositional perspective suggests that narcissists react aggressively to an insult because they are impulsive; there is no internal subjective logic to their behavior, they are simply overcome by impulses that they fail to contain. In this section we begin by providing a summary of the behavioral and biological correlates of impulsivity to set the foundation for examining the parallels between narcissism and impulsivity. Then, we examine and reinterpret narcissists' self-defeating patterns in three domains which have received the most attention from researchers: self-enhancement, aggression, and negative long-term outcomes.

\section{A Portrait of Impulsivity}

To understand how impulsivity can explain narcissists' self-defeating behavior, we must first understand the nature of impulsivity. What do impulsive people do? How strong is the effect of impulsivity on behavior? In this section we provide a brief summary of the biological, behavioral, and life outcome correlates of impulsivity. We will draw on these patterns when reinterpreting narcissists' self-defeating behavior.

As mentioned earlier, the construct of impulsivity goes by many names, including disinhibition 
(Gorenstein \& Newman, 1980), self-control (reversed; Gough, 1956), ego-control (reversed; Block \& Block, 1980), and deliberation (a facet of conscientiousness, reversed; Costa \& McCrae; 1992). It is also closely related, conceptually and empirically, to other constructs such as the inability to delay gratification (Funder, Block, \& Block, 1983; Wulfert, Block, Ana, Rodriguez, \& Colsman, 2002), the behavior inhibition and activation systems (BIS/BAS; Carver \& White, 1994), sensation-seeking (Zuckerman, 1993), psychoticism (Eysenck, 1997), and conscientiousness (reversed; Bogg \& Roberts, 2004).

Self-reports of impulsivity have been validated against informant ratings (e.g., teachers' and parents' ratings), cognitive tests (e.g., Stroop test), and behavioral measures (e.g., impatience and restlessness; White, Moffitt, Caspi, Bartusch, \& Stouthamer-Loeber, 1994). Impulsivity has also been shown to have strong biological underpinnings (Eysenck, 1993; Spinella, 2004; Zuckerman, 2003). For example, impulsivity is linked with decreased levels of serotonin (Harrison, Everitt, \& Robbins, 1999) and specific patterns of activity in the prefrontal cortex (Spinella, 2004), and has been shown to be substantially heritable (Hur \& Bouchard, 1997).

The behavioral and life-outcome correlates of impulsivity are well documented. Relative to nonimpulsive people, impulsive people tend to be more delinquent (Krueger, Caspi, Moffitt, White, \& Slouthamer-Loeber, 1996; White et al., 1994.), engage in more risky sexual behavior (Kahn, Kaplowitz, Goodman, \& Emans, 2002) and driving behavior (Bogg \& Roberts, 2004), engage in more substance abuse (Bogg \& Roberts; Wulfert et al., 2002), have poorer academic performance (Merrell \& Tymms, 2001), be more aggressive (Krueger et al.; Tangney, Baumeister, \& Boone, 2004), be more violent (Bogg \& Roberts), choose short-term over long-term rewards (Funder, Block, \& Block, 1983), be unable to cope with stress or distress (Tangney et al.), and commit more crimes (Wulfert et al., 2002).

In short, impulsivity is a stable disposition with clear biological underpinnings and important and meaningful behavioral outcomes, and is considered a basic dimension of temperament (Clark, in press). This provides more reason to believe that it may play an important explanatory role in narcissists' self-defeating behaviors.

\section{Review of the Narcissism Literature}

In this section we review the major well-established findings on narcissists' self-defeating behavior and evaluate how well narcissists' impulsivity can explain each. We have identified three global areas of research on narcissism: self-enhancement, aggression, and long-term costs. For each of these areas of research, we summarize the findings in the literature and then examine whether narcissists' dispositional impulsivity can provide a parsimonious explanation.

Narcissism and self-enhancement. It is well established that narcissists' self-perceptions are overly positive, almost by definition. Moreover, narcissists' self-deception has a very particular pattern. As Paulhus and John (1998) convincingly argued, narcissists engage primarily in egoistic self-deceptive enhancement. That is, they see themselves as superior on agentic, "superhero-like" traits such as intelligence, dominance, and emotional stability. In contrast they are not likely to see themselves as especially moral, agreeable, or dutiful.

This pattern of self-enhancement is corroborated in many research findings. Narcissism is associated with self-enhancement on agentic traits (Campbell, Rudich, \& Sedikides, 2002), specifically intelligence and ability measures (Campbell et al., 2002; Farwell \& Wohlwend-Lloyd, 1998; Gabriel, Critelli, \& Ee, 1994; Paulhus, Harms, Bruce, \& Lvsy, 2003; Paulhus \& Williams, 2002) and attractiveness (Gabriel et al., 1994). However, narcissists do not self-enhance on communal traits (Campbell et al., 2002) and do not score higher on social-desirability measures (Raskin, Novacek, \& Hogan, 1991a). In addition, narcissists overestimate their contribution to group tasks (John \& Robins, 1994), have positively distorted accounts of their behavior (Gosling, John, Craik, \& Robins, 1998) and of their romantic histories (Rhodewalt \& Eddings, 2002), and are more likely than non-narcissists to make internal attributions for success and external attributions for failure (Campbell, Reeder, Sedikides, \& Elliot, 2000; Kernis \& Sun, 1994; Rhodewalt \& Morf, 1998).

There is also evidence that narcissists' self-delusions are deeply held. Narcissists maintain their overly positive views even in the face of contradictory feedback (Robins \& John, 1997), and hold on to their self-enhancing attributions for success and failure even when doing so comes at the expense of their partner's success in a cooperative task (Campbell, Reeder, Sedikides, \& Elliot, 2000). In addition, narcissists continue to self-enhance even when they know that they will be held accountable for their exaggerations. For example, one study (Paulhus et al., 2003) found that narcissists continued to over-claim (claiming to know about nonexistent items) more than non-narcissists, even when they knew that some of the items they were asked about were nonexistent. In short, narcissists continually overestimate their abilities, positively distort their past behaviors, and hold overly positive views of their personalities, particularly on agentic traits. Moreover, they continue to do so even when such self-presentations put them at social risk.

Why do narcissists exhibit such inappropriate behavior? Morf and Rhodewalt's model (2001) empha- 
sizes the role of faulty thinking patterns. For example, they propose that narcissists seek recognition from others for affective reasons (i.e., to "allay a gnawing concern of inadequacy," p. 179) and for cognitive reasons (i.e., to complete "self-definitional needs," p. 179). However, several lines of research suggest that self-enhancement is linked to dispositional impulsivity.

First, Paulhus and his colleagues (Paulhus, Graf, \& Van Selst, 1989; Paulhus \& Levitt, 1987) have shown that self-enhancement increases when people are distracted by attention tasks or affective stimuli. Participants in these studies completed self-ratings while performing another task (monitoring digits on the computer screen) or being presented with an affective distractor word. Both manipulations decreased participants' self-regulatory resources and led to an increase in the positivity of their self-views. Paulhus and Levitt suggested that people have an "automatic egotism"; a tendency to self-enhance that can only be overridden by effortful processes. This experimental manipulation sheds light on the potential role of dispositional impulsivity in explaining narcissists' persistent self-enhancement. If overly positive self-views are common and automatic, and self-control is necessary to curb people's tendencies to self-enhance, then narcissists' dispositional lack of self-control is likely to account for their excessive and unconstrained self-enhancement.

A similar line of research on self-regulation has found that depleting people's self-regulatory resources induces them to respond more narcissistically. Specifically, Vohs, Baumeister, and Ciarocco (2005) examined the effects of self-regulatory depletion on NPI scores. Their findings show that people whose self-regulatory resources were depleted were more likely to endorse NPI items. Furthermore, self-regulatory depletion was associated with decreases in socially desirable responding, suggesting that depletion is specifically linked to narcissistic self-presentation, not general positive self-presentation. Moreover, the increase in narcissism following depletion was mediated by the decrease in socially desirable responding, suggesting that depletion led to more honest self-presentation, which led to the leaking out of people's narcissistic self-views. This study provides further evidence that narcissists self-enhance because of their impulsivity. Like the participants in the depletion condition, narcissists do not have the self-regulatory resources necessary to curb their inappropriately arrogant self-views. However, in the case of narcissists, their self-regulatory depletion is a chronic, dispositional condition rather than a result of situational pressures.

Narcissism and aggression. Another well-established pattern of self-defeating behavior in narcissists is their aggressiveness, particularly in response to ego threats. Narcissists have been found to respond with anger, hostility, and aggression to bogus negative intelligence feedback (Smalley \& Stake, 1996; Stucke \& Sporer, 2002), social rejection in the laboratory as well as recall of actual social rejection (Twenge \& Campbell, 2003), and being insulted in a laboratory task (Bushman \& Baumeister, 1998). Evidence in the clinical literature also suggests that NPD is associated with real-world aggression (e.g., Warren et al., 2002).

Furthermore, some preliminary evidence suggests that narcissists are more likely to endorse aggression even in the absence of an ego threat. Specifically, male narcissists are more likely than non-narcissists to endorse rape-supportive statements, enjoy watching a film depicting consensual affectionate activity followed by rape, and punish a female confederate for refusing to read a sexually arousing passage aloud to them (Bushman, Bonacci, van Dijk, \& Baumeister, 2003). Narcissists also score higher on self-report measures of hostility (Rhodewalt \& Morf, 1995). In their review of the literature on self-esteem and aggression, Baumeister, Smart, and Boden (1996) conclude that unrealistically high, vulnerable self-esteem (i.e., narcissism) is a contributing factor to aggression in many domains, including self-reported hostility, murder and assault, rape, domestic violence, juvenile delinquency, political violence, and even genocide.

What makes narcissists aggressive? The cognitive-processes explanation of narcissists' aggression is based on a fundamental assumption that there must be some internal subjective logic to the aggressive behavior of narcissists (e.g., Baumeister et al., 2000). However, a strong argument can also be made for a dispositional influence. Knowing that narcissists are impulsive, that impulsivity is linked to aggression, and that impulsivity is a biologically-based temperament that exerts strong influences on behavior, it is reasonable to suppose that narcissists' aggression is due in part to their impulsive temperament. Furthermore, Stucke and Sporer (2002) found that emotional reactions did not mediate the relationship between narcissism and aggression, suggesting that affective appraisals do not account for narcissists' aggression. We suspect, however, that both impulsivity and cognitive and affective appraisals play an important role in narcissists' aggression.

Narcissism and negative long-term outcomes. A third pattern characteristic of narcissists is that they engage in behaviors that provide short-term benefits but lead to negative long-term outcomes. This is true in the domains of interpersonal relationships, adjustment, and achievement.

In the interpersonal domain, narcissists tend to make positive first impressions but become disliked once others get to know them. Paulhus (1998) exam- 
ined the quality of narcissists and non-narcissists' interpersonal relations in newly-formed groups over a 7 -week period. Narcissism was operationalized in two ways: as the discrepancy between self-ratings and friends' ratings of personality, and as measured by the NPI. Both measures of narcissism revealed the same pattern: narcissists were perceived as agreeable, well-adjusted, and competent upon first meeting their group members, but their reputations deteriorated over time and by Week 7 they were perceived negatively. These results suggest that the same behaviors that elicit immediate positive reactions from others lead narcissists to suffer negative long-term consequences in the interpersonal domain.

Paulhus (1998) also found that narcissism was associated with higher self-esteem. As he and others have pointed out, however, such self-reports may be affected by self-enhancement, and other measures of adjustment would provide a better test of the relationship between narcissism and psychological adjustment. Colvin and colleagues (1995) provided a more rigorous test of the long-term consequences of narcissism on psychological adjustment by examining the relationship between self-enhancement and clinician-rated adjustment, each measured 5 years apart. Their findings show that self-enhancement was associated with poorer psychological adjustment 5 years before and 5 years after self-enhancement was measured.

Other evidence suggests that narcissistic self-enhancement provides short-term boosts in well-being. Robins and Beer (2001) found that narcissists were more likely to make self-serving attributions after a group task, and that these positive illusions were associated with greater positive affect after the task. This finding suggests that the same behaviors that are associated with long-term psychological maladjustment are also associated with short-term boosts in well-being.

Finally, this pattern can also be found in the academic domain. Robins and Beer (2001) also found that narcissists hold unrealistically high expectations of their own achievement, leading to positive short-term outcomes but negative long-term consequences. Specifically, those whose predictions about their college GPA were unrealistically high were especially likely to experience positive affect, high ego-involvement, and self-serving attributions at the time the predictions were made. However, when the self-enhancers were assessed again over their 4 years of college, they exhibited declining levels of self-esteem, well-being, and engagement in the academic domain relative to nonself-enhancers.

In summary, narcissists engage in behaviors that provide immediate gratification of their desires for social status, positive affect, and ego-involvement in achievement domains, but they do so at the cost of fulfilling these desires in the long-term. In one study, Helgeson and Fritz (1999) found that unmitigated agency (overly positive self-views on agentic traits, i.e., narcissism) was associated with self-reports of negative interactions with friends and family, hostility, anxiety, negative well-being, and negative health behaviors. This reflects the havoc that narcissism can wreak on the quality of one's interpersonal relations and psychological and physical health.

Why do narcissists sacrifice the long-term fulfillment of their goals in favor of immediate gratification? The most parsimonious explanation would seem to be that narcissists' impulsivity prevents them from delaying gratification even when it is beneficial to do so (and costly not to). Indeed, the inability to delay gratification is one of the defining characteristics of impulsivity, and is linked to many negative outcomes (Cooper, Wood, Orcutt, \& Albino, 2003; Krueger et al., 1996; White et al., 1994). Once again, expanding Morf and Rhodewalt's (2001) model to include dispositional impulsivity as a predictor of narcissists' behavior appears to improve its explanatory power.

Summary. Table 2 presents a summary of the three main areas of research we have reviewed here, and the parallels between narcissism and impulsivity in those three areas. We have focused on the self-defeating behavioral patterns of narcissists that have received the most attention in the literature. Surely many other studies of narcissists do not fall into these three categories, but these represent the most commonly studied and well-established behavioral patterns.

Narcissists' characteristic patterns of self-enhancing, aggressive, and short-sighted behavior are all consistent with our proposal that narcissists' impulsivity

Table 2. Behavioral Parallels Between Narcissism and Impulsivity.

\begin{tabular}{lcc}
\hline Behavior & Narcissism & Impulsivity \\
\hline Self-enhancement & $\begin{array}{c}\text { Narcissists self-enhance even when } \\
\text { inappropriate. } \\
\text { Narcissists react aggressively (particularly to } \\
\text { ego-threat). }\end{array}$ & $\begin{array}{c}\text { Self-regulatory depletion leads to } \\
\text { self-enhancement ("automatic egotism"). } \\
\text { Impulsivity is linked to aggression. }\end{array}$ \\
$\begin{array}{l}\text { Negative long-term outcomes/ } \\
\text { immediate gratification }\end{array}$ & $\begin{array}{c}\text { long-term costs in interpersonal, } \\
\text { adjustment, and achievement domains. }\end{array}$ & gratification \\
& Impulsivity is linked to the inability to delay
\end{tabular}


accounts in part for their behavior. Specifically, each of these three patterns of behavior is also typical of people high in impulsivity. Given the strong empirical relationship between narcissism and impulsivity (Table 1), the most parsimonious explanation for these behaviors is that they are influenced, in part, by narcissists' impulsivity. Based on the evidence we have provided here, we suggest that Morf and Rhodewalt's (2001) model of narcissism should be expanded to include dispositional impulsivity as a predictor of narcissists' behaviors. Clearly the predictors that are already in the model, such as goals, appraisals, and self-concepts, also play an important role, but the model is incomplete without dispositional variables, and specifically impulsivity.

The link between narcissism and impulsivity should also be taken into account when interpreting other (i.e., nonbehavioral) research on narcissism. For example, there is a great deal of research on the distinction between narcissism and high self-esteem (e.g., Jordan et al., 2003; Rhodewalt, Madrian, \& Cheney, 1998; Smalley \& Stake, 1996). This research has identified several important ways in which narcissism differs from high self-esteem. Impulsivity, which is positively correlated with narcissism (Table 1) but not self-esteem ( $r=-.19$, n.s.; Vazire \& Mehl, 2004), may be another piece of the puzzle. That is, researchers may be able to use impulsivity as a tool in distinguishing between narcissism and high self-esteem.

In summary, we have presented evidence for our proposal in two steps. First, our meta-analysis demonstrated an empirical link between narcissism and impulsivity. Second, we demonstrated how three important behavioral patterns of narcissists can be explained in terms of narcissists' impulsivity. Taken together, these pieces of evidence suggest that impulsivity provides a parsimonious explanation for many of the behavioral (and potentially some of the nonbehavioral) correlates of narcissism.

Future directions. Our meta-analysis and review of the literature provide a strong argument for incorporating impulsivity into our understanding of narcissism. However, new and improved techniques for assessing impulsivity and self-control have emerged because many of the studies in our meta-analysis were conducted. Thus, our first recommendation for future research is that studies examining narcissism should include multiple well-validated measures of impulsivity. For example, researchers could obtain self- and informant-reports on the ego undercontrol scale (Letzring et al., in press) and administer laboratory-based tests of self-control (see Vohs et al., 2005, for examples). This will allow further tests of our hypothesis, and will also allow researchers to examine whether impulsivity accounts for some of the differ- ences between narcissists and nonnarcissists in their studies.

Researchers interested in narcissism should also pay special attention to the role that impulsivity plays in the phenomena they study. For example, research interested in the narcissism-aggression link should be sure to include measures of impulsivity and examine whether impulsivity mediates the link between narcissism and aggression.

There are also several unresolved questions about the nature of the relationship between impulsivity and narcissism which should be addressed in future research. First, does narcissists' impulsivity result from an excess of desires (e.g., unusually high need for power) or from a shortage of restraints (e.g., low self-regulatory resources)? Future research could address this by administering scales that differentiate between approach and inhibition systems (e.g., the BIS/ BAS scales; Carver \& White, 1994), and examining their relationship to narcissism.

Another question to be addressed in future research is whether the relationship between impulsivity and narcissism is universal. If it is the case that "automatic egotism" is a universal tendency, we would expect this relationship to be true across cultures. However, if there are cultural differences in the automaticity and prevalence of self-enhancement motives, it is likely that impulsivity would not be associated with narcissism in all cultures. That is, impulsivity should be associated with whatever motive is strongest in a given context. Future research should examine the relationship between impulsivity and narcissism across cultures, and continue to examine cultural differences in self-enhancement motives (e.g., Heine, Takata, \& Lehman, 2000; Kobayashi \& Brown, 2003).

Finally, the directional relationship between impulsivity and narcissistic behavior should be examined in greater detail. The correlational data presented here cannot address whether impulsivity causes narcissists' self-defeating behavior. Although some experimental research has shown that depleting self-regulatory resources leads to narcissistic behavior (Vohs et al., 2005), further experimentation is needed to determine the causal nature of the relationship.

\section{Conclusion}

We return now to the original question that motivates much of the research on narcissism: Why do narcissists engage in behaviors that undermine their urgent goals of power and recognition? We have argued here that sometimes the answer may be very simple: Because they can't help it. The paradoxical behavior of narcissists, such as their limitless self-enhancement, counterproductive aggression, and preference for 
short-term immediate gratification over long-term benefits may be driven in part by their dispositional impulsivity.

Although impulsivity has long been recognized as a correlate of narcissism, it has been overlooked as an important influence on and explanation for narcissists' behavior. Our meta-analysis and review of the literature suggests that impulsivity should be included in models of narcissism, and that researchers should consider impulsivity as a possible explanatory variable when interpreting narcissists' self-defeating behaviors.

\section{References}

References marked with an asterisk indicate studies included in the meta-analysis.

Baumeister, R. F., Bushman, B. J., \& Campbell, W. K. (2000). Narcissism, self-esteem, and aggression: Does violence result from low self-esteem or from threatened egotism? Current Directions in Psychological Science, 9, 26-29.

Baumeister, R. F., Smart, L., \& Boden, J. M. (1996). Relation of threatened egotism to violence and aggression: The dark side of high self-esteem. Psychological Review, 103, 5-33.

Block, J. (1961). The Q-Sort method in personality assessment and psychiatric research. Palo Alto, CA: Consulting Psychologists Press.

Block, J. (2002). Personality as an affect-processing system. Mahwah, NJ: Lawrence Erlbaum Associates, Inc.

Block, J. H., \& Block, J. (1980). The role of ego-control and ego-resiliency in the organization of behavior. In W. A. Collins (Ed.), The Minnesota Symposium on Child Psychology: Vol. 13. Development of cognition, affect, and social relations (pp. 39-101). Hillsdale, NJ: Lawrence Erlbaum Associates, Inc.

Bogg, T., \& Roberts, B. W. (2004). Conscientiousness and health-related behaviors: A meta-analysis of the leading behavioral contributors to mortality. Psychological Bulletin, 130, 887-919.

Bushman, B. J., \& Baumeister, R. F. (1998). Threatened egotism, narcissism, self-esteem, and direct and displaced aggression: Does self-love or self-hate lead to violence? Journal of Personality and Social Psychology, 75, 219-229.

Bushman, B. J., Bonacci, A. M., van Dijk, M., \& Baumeister, R. F. (2003). Narcissism, sexual refusal, and aggression: Testing a narcissistic reactance model of sexual coercion. Journal of Personality and Social Psychology, 84, 1027-1040.

Campbell, W. K., Reeder, G. D., Sedikides, C., \& Elliot, A. J. (2000). Narcissism and comparative self-enhancement strategies. Journal of Research in Personality, 34, 329-347.

Campbell, W. K., Rudich, E. A., \& Sedikides, C. (2002). Narcissism, self-esteem, and the positivity of self-views: Two portraits of self-love. Personality and Social Psychology Bulletin, 28, 358-368.

Carver, C. S., \& White, T. L. (1994). Behavioral inhibition, behavioral activation, and affective responses to impending reward and punishment: The BIS/BAS scales. Journal of Personality and Social Psychology, 67, 319-333.

Casillas, A., \& Clark, L. A. (2002). Dependency, impulsivity, and self-harm: Traits hypothesized to underlie the association between cluster B personality and substance use disorders. Journal of Personality Disorders, 16, 424-436.

Clark, L. A. (1993). Schedule for Nonadaptive and Adaptive Personality (SNAP). Minneapolis: University of Minnesota Press.
Clark, L. A. (in press). Temperament as a unifying basis for personality and psychopathology. Journal of Abnormal Psychology.

*Colvin, C. R., Block, J., \& Funder, D. C. (1995). Overly positive self-evaluations and personality: Negative implications for mental health. Journal of Personality and Social Psychology, 68, 1152-1162.

Cooper, M. L., Wood, P. K., Orcutt, H. K., \& Albino, A. (2003). Personality and the predisposition to engage in risky or problem behaviors during adolescence. Journal of Personality and Social Psychology, 84, 390-410.

Costa, P. T., Jr., \& McCrae, R. R. (1992). Normal personality assessment in clinical practice: The NEO Personality Inventory. Psychological Assessment, 4, 5-13.

*Emmons, R. A. (1984). Factor analysis and construct validity of the Narcissistic Personality Inventory. Journal of Personality Assessment, 48, 291-300.

Eysenck, H. J. (1993). The nature of impulsivity. In W. J. McCown, J. L. Johnson, \& M. B. Shure (Eds.), Impulsive client: Theory, research, and treatment (pp. 71-91). Washington, DC: American Psychological Association.

Eysenck, S. (1997). Psychoticism as a dimension of personality. In H. Nyborg (Ed.), Scientific study of human nature: Tribute to Hans J. Eysenck at eighty (pp. 109-121). Amsterdam: Pergamon/Elsevier Science.

Farwell, L., \& Wohlwend-Lloyd, R. (1998). Narcissistic processes: Optimistic expectations, favorable self-evaluations, and self-enhancing attributions. Journal of Personality, 66, 65-83.

*Funder, D. C. (2004). [The Riverside Accuracy Project, Phase II]. Unpublished raw data.

Funder, D. C., Block, J. H., \& Block, J. (1983). Delay of gratification: Some longitudinal personality correlates. Journal of Personality and Social Psychology, 44, 1198-1213.

Gabriel, M. T, Critelli, J. W., \& Ee, J. S. (1994). Narcissistic illusions in self-evaluations of intelligence and attractiveness. Journal of Personality, 62, 143-155.

Gorenstein, E. E., \& Newman, J. P. (1980). Disinhibitory psychopathology: A new perspective and a model for research. Psychological Review, 87, 301-315.

Gosling, S. D., John, O. P., Craik, K. H., \& Robins, R. W. (1998). Do people know how they behave? Self-reported act frequencies compared with on-line codings by observers. Journal of Personality and Social Psychology, 74, 1337-1349.

Gough, H. G. (1956). The California Psychological Inventory. Palo Alto, CA: Consulting Psychologists Press.

Harrison, A. A., Everitt, B. J., \& Robbins, T. W. (1999). Central serotonin depletion impairs both the acquisition and performance of symmetrically reinforced go/no-go conditional visual discrimination. Behavioural Brain Research, 100, 99-112.

Heine, S. J., Takata, T., \& Lehman, D. R. (2000). Beyond self-presentation: Evidence for self-criticism among Japanese. Personality and Social Psychology Bulletin, 26, 71-78.

Helgeson, V. S., \& Fritz, H. L. (1999). Unmitigated agency and unmitigated communion: Distinctions from agency and communion. Journal of Research in Personality, 33, 131-158.

Hollander, E., \& Rosen, J. (2000). Impulsivity. Journal of Psychopharmacology, 14, 39-44.

Hur, Y., \& Bouchard, T. J., Jr. (1997). The genetic correlation between impulsivity and sensation seeking traits. Behavior genetics, 27, 455-463.

John, O. P., \& Robins, R. W. (1994). Accuracy and bias in self-perception: Individual differences in self-enhancement and the role of narcissism. Journal of Personality and Social Psychology, 66, 206-219.

Jordan, C. H., Spencer, S. J., Zanna, M. P., Hoshino-Browne, E., \& Correll, J. (2003). Secure and defensive high self-esteem. Journal of Personality and Social Psychology, 85, 969-978. 
Kahn, J. A., Kaplowitz, R. A., Goodman, E., \& Emans, S. J. (2002). The association between impulsiveness and sexual risk behaviors in adolescent and young adult women. Journal of Adolescent Health, 30, 229-232.

Kernis, M. H., \& Sun, C. R. (1994). Narcissism and reactions to interpersonal feedback. Journal of Research in Personality, 28,4-13.

Kobayashi, C., \& Brown, J. D. (2003). Self-esteem and self-enhancement in Japan and America. Journal of Cross-Cultural Psychology, 34, 567-580.

Krueger, R. F., Caspi. A., Moffitt, T. E., White, J., \& Stouthamer-Loeber, M. (1996). Delay of gratification, psychopathology, and personality: Is low self-control specific to externalizing problems? Journal of Personality, 64, 107-129.

Kurt, A., \& Paulhus, D. L. (2004). Moderators of the adaptive value of self-enhancement: Operationalization, domain, and adjustment criterion. Manuscript submitted for publication.

Letzring, T. D., Block, J., \& Funder, D. C. (in press). Ego-control and ego-resiliency: Generalization of self-report scales based on personality descriptions from acquaintances, clinicians, and the self. Journal of Research in Personality.

Merrell, C., \& Tymms, P. B. (2001). Inattention, hyperactivity, and impulsiveness: Their impact on academic achievement and progress. British Journal of Educational Psychology, 71, 43-56.

Mischel, W., \& Ayduk, O. (2002). Self-regulation in the cognitive-affective personality system: Attentional control in the service of the self. Self and Identity, 1, 113-120.

Morf, C. C., \& Rhodewalt, F. (2001). Unraveling the paradoxes of narcissism: A dynamic self-regulatory processing model. Psychological Inquiry, 12, 177-196.

Patton, J. H., Stanford, M. S., \& Barratt, E. S. (1995). Factor structure of the Barratt Impulsiveness Scale. Journal of Clinical Psychology, 51, 768-774.

Paulhus, D. L. (1998). Interpersonal and intrapsychic adaptiveness of trait self-enhancement: A mixed blessing? Journal of Personality and Social Psychology, 74, 1197-1208.

Paulhus, D. L., Graf, P., \& van Selst, M. (1989). Attentional load increases the positivity of self-presentations. Social Cognition, 7, 389-400.

Paulhus, D. L., Harms, P. D., Bruce, M. N., \& Lvsy, D. C. (2003). The over-claiming technique: Measuring self-enhancement independent of ability. Journal of Personality and Social Psychology, 84, 890-904.

Paulhus, D. L., \& John, O. P. (1998). Egoistic and moralistic bias in self-perception: The interplay of self-deceptive styles with basic traits and motives. Journal of Personality, 66, 1025-1060.

Paulhus, D. L., \& Levitt, K. (1987). Desirable responding triggered by affect: Automatic egotism? Journal of Personality and Social Psychology, 52, 245-259.

Paulhus, D. L., \& Williams, K. M. (2002). The dark triad of personality: Narcissism, machiavellianism, and psychopathy. Journal of Research in Personality, 36, 556-563.

*Raskin, R., \& Novacek, J. (1989). An MMPI description of the narcissistic personality. Journal of Personality Assessment, 53, $66-80$.

Raskin, R., Novacek, J., \& Hogan, R. (1991a). Narcissism, self-esteem, and defensive self-enhancement. Journal of Personality, 59, 19-38.

Raskin, R., Novacek, J., \& Hogan, R. (1991b). Narcissistic self-esteem management. Journal of Personality and Social Psychology, 60, 911-918.

*Raskin, R., \& Terry, H. (1988). A principal-components analysis of the Narcissistic Personality Inventory and further evidence of its construct validity. Journal of Personality and Social Psychology, 54, 890-902.

Rhodewalt, F., \& Eddings, S. K. (2002). Narcissus reflects: Memory distortion in response to ego-relevant feedback among high- and low-narcissistic men. Journal of Research in Personality, $36,97-116$

Rhodewalt, F., Madrian, J. C., \& Cheney, S. (1998). Narcissism, self-knowledge organization, and emotional reactivity: The effect of daily experiences on self-esteem and affect. Personality and Social Psychology Bulletin, 24, 75-87.

Rhodewalt, F., \& Morf, C. C. (1995). Self and interpersonal correlates of the Narcissistic Personality Inventory: A review and new findings. Journal of Research in Personality, 29, 1-23.

Rhodewalt, F., \& Morf, C. C. (1998). On self-aggrandizement and anger: A temporal analysis of narcissism and affective reactions to success and failure. Journal of Personality and Social Psychology, 74, 672-685.

Robins, R. W., \& Beer, J. S. (2001). Positive illusions about the self: Short-term benefits and long-term costs. Journal of Personality and Social Psychology, 80, 340-352.

Robins, R. W., \& John, O. P. (1997). Effects of visual perspective and narcissism on self-perception: Is seeing believing? Psychological Science, 8, 37-42.

Rosenthal, R. (1995). Writing meta-analytic reviews. Psychological Bulletin, 118, 183-192.

Smalley, R. L., \& Stake, J. E. (1996). Evaluating sources of ego-threatening feedback: Self-esteem and narcissism effects. Journal of Research in Personality, 30, 483-495.

Spinella, M. (2004). Neurobehavioral correlates of impulsivity: Evidence of prefrontal involvement. International Journal of Neuroscience, 114, 95-104.

Stucke, T. S., \& Sporer, S. L. (2002). When a grandiose self-image is threatened: Narcissism and self-concept clarity as predictors of negative emotions and aggression following ego-threat. Journal of Personality, 70, 509-532.

Tangney, J. P., Baumeister, R. F., \& Boone, A. L. (2004). Higher self-control predicts good adjustment, less pathology, better grades, and interpersonal success. Journal of Personality, 72, 271-322.

Twenge, J. M., \& Campbell, W. K. (2003). "Isn't it fun to get the respect that we're going to deserve?" Narcissism, social rejection, and aggression. Personality and Social Psychology Bulletin, 29, 261-272.

*Vazire, S., \& Mehl, M. R.(2004). [Self-reports, informant reports, and the prediction of behavior]. Unpublished raw data.

Vohs, K. D., Baumeister, R. F., \& Ciarocco, N. J. (2005). Self-regulation and self-presentation: Regulatory resource depletion impairs impression management and effortful self-presentation depletes self-regulatory resources. Journal of Personality and Social Psychology, 88, 632-657.

Warren, J. I., Burnette, M., South, S. C., Chauhan, P., Bale, R., \& Friend, R. (2002). Personality disorders and violence among female prison inmates. Journal of the American Academy of Psychiatry and the Law, 30, 502-509.

Westen, D. (1990). The relations among narcissism, egocentrism, self-concept, and self-esteem. Psychoanalysis and Contemporary Thought, 13, 185-241.

White, J. L., Moffitt, T. E., Caspi. A., Bartusch, D. J., \& Stouthamer-Loeber, M. (1994). Measuring impulsivity and examining its relationship to delinquency. Journal of Abnormal Psychology, 103, 192-205.

*Wink, P. (1991). Two faces of narcissism. Journal of Personality and Social Psychology, 61, 590-597.

*Wink, P. (1992). Three narcissism scales for the California Q-Set. Journal of Personality Assessment, 58, 51-66.

*Wink, P., \& Donahue, K. (1997). The relation between two types of narcissism and boredom. Journal of Research in Personality, 31, 136-140.

*Wink, P., \& Gough, H. G. (1990). New narcissism scales for the California Psychological Inventory and the MMPI. Journal of Personality Assessment, 54, 446-462. 


\section{NARCISSISM AND IMPULSIVITY}

Wulfert, E., Block, J. A., Ana, E. S., Rodriguez, M. L., \& Colsman, M. (2002). Delay of gratification: Impulsive choices and problem behaviors in early and late adolescence. Journal of Personality, 70, 533-552.

Zuckerman, M. (1993). Sensation seeking and impulsivity: A marriage of traits made in biology? In W. J. McCown, J. L. Johnson,
\& M. B. Shure (Eds.) Impulsive client: Theory, research, and treatment (pp. 71-91). Washington, DC: American Psychological Association.

Zuckerman, M. (2003). Biological bases of personality. In T. Millon \& M. J. Lerner (Eds.), Handbook of psychology: Vol. 5. Personality and social psychology (pp. 85-116). New York: Wiley. 